(C) Dr W. Junk Publishers, Dordrecht - Printed in the Netherlands

\title{
Ecophysiological studies of Halidrys siliquosa in relation to observed changes in natu- ral populations
}

C. S. Larsson*, T. Lundälv \& L. Axelsson

Kristineberg Marine Biological Station, 5-450 34 Fiskebëckskil, Sweden

*also University of Göteborg, Dept. of Marine Botany

An ecophysiological study of the brown algae $H$. siliquosa has been initiated in order to evaluate if changes in abiotic conditions could be responsible for a massive decrease in the populations of this algal species. Such a decrease occurred in several localities during the years 1979-81 along the Swedish west coast. The first purpose was to study factors determining the northern limit of the alga's distribution. $H$. siliquosa, with its main distribution to the south, has been compared to the closely related and morphologically similar Ascophyllum nodosum, f scorpioides, which has a more northern distribution. This comparison revealed the following differences between the two algal species:
Irradiation in stagnant water resulted in much higher photooxidative damage on $H$. siliquosa (both reversible and irreversible). This alga is thus more sensitive to a combination of high irradiation, low temperature and low water motion.

$H$. siliquosa showed lower rates of bicarbonate uptake, especially at lower temperatures, and in stagnant water. In addition, $H$. siliquosa lacked a light buffering system which occurs in other members of Fucales growing on the Swedish west coast. Also, in the northern regions, the alga occurs only close to the surface. These last facts suggest that the conservation of light energy is the critical factor. 